Final Report

FHWA/IN/JTRP-2006/12

\title{
BLIND PEDESTRIANS AND THEIR ABILITY TO NAVIGATE INDIANA INTERSECTIONS - A REVIEW OF THE TECHNOLOGY AVAILABLE FOR AUDIBLE SIGNALS
}

\author{
By \\ Robert B. Jacko \\ Principal Investigator \\ Professor of Civil Engineering \\ Purdue University \\ Joint Transportation Research Program \\ Project No. C-36-59NN \\ File No. $8-5-40$ \\ SPR-2946 \\ Conducted in Cooperation with the \\ Indiana Department of Transportation \\ and the U.S. Department of Transportation \\ Federal Highway Administration
}

The contents of this report reflect the views of the author who is responsible for the facts and accuracy of the data presented herein. The contents do not necessarily reflect the official views or policies of the Indiana Department of Transportation and the Federal Highway Administration. This report does not constitute a standard, specification, or regulation.

Purdue University

West Lafayette, Indiana

May 2006 
TABLE OF CONTENTS

Page

LIST OF FIGURES .............................................. 3

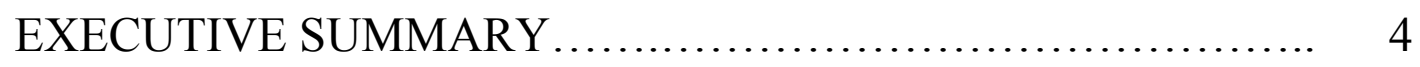

INTRODUCTION ......................................... 5

NAVIGATIONAL NEEDS OF A BLIND PEDESTRIAN......... 6

STATUS OF A UNITED STATES ACCESSIBLE

PEDESTRIAN SIGNAL HARDWARE STANDARD ...... 7

BLIND INDIANA CITIZEN PETITION FOR ACCESSIBLE PEDESTRIAN SIGNALS - A CASE HISTORY ............ 8

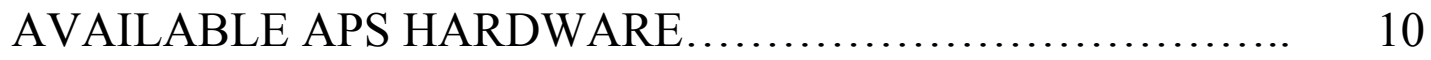

POLARA $®$ SYSTEM SITE VISIT AT MIAMI, Fl ............... 11

TWO EXAMPLES OF AN APS SPECIFICATION ............... 13

INTERSECTION RATING WORKSHEETS FOR APS........... 20

INSTALLATION OF POLARA SYSTEM AT PURDUE......... 21

SUMMARY ................................................ 26 


\section{LIST OF FIGURES}

Figure 1 Intersection Rating Worksheet for APS (1) .......................... 20

Figure 2 Intersection Rating Worksheet for APS (2)............................ 21

Figure 3 Blind pedestrian finds push button on pole using locating tone........ 22

Figure 4 Blind Pedestrians with Guide Dogs Activate APS by Pushing Button.. 22

Figure 5 Blind Pedestrians Initiate Crossing on Audible "Walk Sign is

On"(repeated three times followed by time countdown............................ 23

Figure 6 Traffic Technician Programs APS circuitry with Wireless hand held remote ............................................................................. 23

Figure7 Disassembly of Speaker/Push Button Box............................... 24

Figure 8 Removal of Printed Sign From APS Push Button Box.................. 25

Figure 9 Circuitry Exposed in Speaker/Push Button Box....................... 25

Figure 10 Polara Navigator Control Box Located in Traffic Cabinet.............. 26 


\section{EXECUTIVE SUMMARY}

Accessible pedestrian signals (APS) that combine audible and vibrotactile signals to a blind or visually impaired and/or disabled pedestrian for both locational and navigational information are available for purchase and installation "off the shelf". APS systems that have a locating tone, produce an audible language statement when it is safe to begin crossing the intersection as well as a vibrating activation button for the hard of hearing and an audible status count-down for the crossing pedestrian are available now. Purdue University has retrofitted two campus intersections with audible, vibrotactile APS and the intersections are regularly used by blind students. Discussions with the West Lafayette technician assigned to maintain the signals has indicated that the APS buttons alone are much more robust than the standard small buttons at non APS intersections. If an intersection already has traffic signal lights, the cost to install a two wire Polara ${ }^{\circledR}$ APS on the four corners would be approximately $\$ 500.00$ per corner for hardware plus the labor of two men for about four hours. The total cost is certainly a very small percentage of the costs to renovate an existing traffic signal intersection involving new lights, pavement, curbs, gutters and storm drains, etc.

Presentations to a number of blind organizations throughout Indiana regarding APS over the duration of this research project has uncovered a real need by the blind for pedestrian intersection navigational hardware. However, a seminar given to engineers from the traffic signal division of INDOT indicates that the lack of a national standard for such APS hardware is a serious impediment to the installation of APS at intersections designated as Indiana state highways. It is the engineering opinion of this author that until a national standard is published by the Federal Access Board, the installation of Accessible Pedestrian Signals on Indiana state highway right-of-ways will not happen. Discussion with the new vice-chair and a staff member of the United States Access Board at a recent national ADA conference in Miami, Fl, lead to their prediction that a national standard is about three years away. This is disappointing to the blind community since accessible pedestrian signals at problematic intersections will prevent injuries and save lives.

Note: At its March 2006 meeting, theU.S. Access Board also elected public member James R. ("J.R.") Harding, II Ed.D. as vice chair. Harding, of Tallahassee, Florida, was appointed to the Board by President Bush in 2002. He is a Partnership Specialist with the Florida Department of Education's Division of Vocational Rehabilitation. 


\section{Introduction}

Accessibility means that any American citizen, disabled in any way, has a civil right to those services and amenities enjoyed by a non-disabled citizen. This civil rights concept was codified in the Americans with Disabilities Act signed into law by President George H. Bush in 1990. This law is framed after earlier civil rights laws prohibiting discrimination on the basis of race and gender. Early implementation of the ADA law is evidenced by curb cuts for those in wheel chairs, electric door openers and ramps leading into buildings which are used by the general public. Often these ADA modifications are also very useful and convenient to the user who may not be disabled and herein, in the opinion of this author, is the latent benefit of these accessibility standards.

Under the ADA, the United States Access Board made up of Presidential appointees, has developed and continues to maintain design guidelines for accessible buildings and facilities known as the ADA Accessibility Guidelines (ADAAG). These guidelines apply to any facility designed, built, altered or leased with Federal funds. The Access Board also has a similar responsibility for accessibility guidelines under the Architectural Barriers Act (ABA). ABA, like the ADAAG applies to new construction and alterations.

The second draft of the accessibility guidelines was recently released by the U.S. Access Board on November 23, 2005 and can be viewed on the web at www.accessboard.gov . This draft II is entitled "Notice of Availability of Draft Public Rights-ofWay Accessibility Guidelines". In this document, each topic specific paragraph is identified with a number preceded by the letter "R". This letter R stands for "Right of Way". Accessible Pedestrian Signals (APS) for the blind and visually impaired appear in paragraph R208 on page 10 and specifically require that APS's incorporate audible and vibrotactile features. Additionally, paragraph R210 also on page 10 requires Braille street name signage on APS pedbuttons.

\section{NAVIGATIONAL NEEDS OF A BLIND PEDESTRIAN AT A ROADWAY INTERSECTION}

Orientation and Mobility specialists train blind and visually impaired persons to navigate pedestrian intersections using traffic sounds and directionality of sound in

helping the blind person to know when to cross an intersection. However, many 
intersections are very problematic and dangerous for a blind person to navigate without additional navigation aids. Unless the blind person is familiar with a particular intersection and has memorized the specific near route to the crosswalk, a sighted guide would be needed to locate the person at the crosswalk and in a direction aligned with the crosswalk. At an intersection without additional navigational aids, the blind person traditionally would listen for the traffic starting up parallel to their walking direction. The blind person now proceeds to cross the intersection assuming the traffic perpendicular to his/her walking direction has stopped since the traffic on the parallel street is accelerating. The problem with this is the right turn on red which may expose the blind person to a moving vehicle in their walking path. Although most states have a white cane law which states that a motorist come to a full stop when a person with a white cane or dog guide is spotted in a crosswalk, most motorists are either ignorant of this law or choose to ignore it. The motorist lack of recognition of a disabled or blind pedestrian at the entrance to a crosswalk a is a matter of education and enforcement by the motor vehicle departments and police but the civil engineer can play a profound role in getting the blind person safely to and across problematic intersections.

The basic elements of a navigational system that would be of immense help to the blind pedestrian are as follows (1) a locating tone to find the crosswalk with a vibrotactile push button aligned in a standard way so that the person can readily identify the direction of travel into the crosswalk; (2) an additional audible signal or statement to know when to cross ; (3) while crossing, an audible status should be given of the time remaining in the walk cycle and (4) when approximately halfway across the intersection, the audible signal should now be heard coming from the end of the crosswalk toward which the person is walking. The elements of this navigational aid are clearly specified in the Access Board Draft II Guidelines (www.access.board.gov) which were published in November 23, 2005. These navigational elements help the blind pedestrian find the pedestrian crosswalk, orients the person into the proper crossing direction, tells the person both audibly and in a tactile way (vibrating button for the hard of hearing) when it is safe to start crossing, audibly enunciates the time left for crossing, and presents the countdown in such a way that the blind person at the halfway crossing point begins to hear the countdown emanating from their target crossing point in front of them. This countdown that the blind person hears coming to them from a point not behind them but in front, gives them a directional aid as well.

\section{STATUS OF A UNITED STATES ACCESSIBLE PEDESTRIAN SIGNAL HARDWARE STANDARD}

The state of Indiana is very reluctant to institute a program of accessible pedestrian signal hardware installations without a national standard specifying the details of such hardware and the corresponding installation protocol. An informational seminar was given by this 
author on Friday, December 2, 2005 at the Indiana Government Center, South, conference room 5 to discuss accessible pedestrian signals with INDOT engineers. In addition to this author, Mr. Dennis Steele the West Lafayette Street Department technician who has responsibility for operation and maintenance of two Polara ${ }^{\circledR}$ accessible pedestrian signals on the Purdue campus accompanied me to the seminar. Fourteen INDOT personnel attended the seminar representing traffic signal design, sign design, lighting design and operations support. Attendees came from Indianapolis, Greenfield, Vincennes and Seymour, IN. Discussion during the three hour seminar revealed the impediment to the installation of APSs in Indiana. This impediment was the lack of a state or federal standard defining such systems.

This author was scheduled to attend a conference sponsored by the National Association of ADA Coordinators during the week of October 24, 2005 in order to obtain the latest information on the U.S. Access board APS standards development. Hurricane Wilma hit south Florida that week and the conference was rescheduled for March 6-9, 2006 which this author did attend. Both the vice-chair of the U.S. Access Board, James R. ("J.R.") (accessibility specialist) were present at the conference. Dr. Harding, II was recently appointed by President Bush to the Access Board. Dr. Harding is a Partnership Specialist with the Florida Department of Education's Division of Vocational Rehabilitation. I engaged both Dr. Harding and Mr. Windley in a sidebar discussion regarding when the U.S. Access Board will be promulgating the new standards for APSs. Their reply was "in about three years". This was disappointing to me since I know from speaking with the blind and visually impaired community throughout Indiana that such APS hardware is sorely needed to prevent injury and deaths to blind pedestrians at problematic intersections in Indiana. Keep in mind that in the United States in 2002, more than 4,800 pedestrians were killed in traffic accidents and another 71,000 were injured. Of these, $17 \%$ were senior citizen fatalities ( 70 years of age or older) and $6 \%$ were senior citizen injuries. One-in-four persons in this age bracket probably had some form of visual impairment and it is possible that APSs might have saved the lives of 200 senior citizens and prevented the injuries of another 1000 senior citizens had APSs been installed at problematic intersections in the United States in 2002.

Keep in mind that the blind are not the only segment of our society that are aided by APSs. The deaf and hearing impaired will also benefit from this technology. This fact was strongly brought out at one of my statewide-seminars to blind groups. 


\section{BLIND INDIANA CITIZEN PETITION FOR ACCESSIBLE PEDESTRIAN SIGNALS - A CASE HISTORY}

(by Mr. Greg Meyer, Indianapolis resident)

Why do I want to get across the road? Too get to the other side. If only it was that easy. The next few paragraphs will entail a history of trying to make the intersection of U.S. 40 and Post Road accessible for people with disabilities.

July 2003: $\quad$ I contacted Indianapolis Dept. of Public Works and was told this intersection was not their responsibility. I was told INDOT was the one I needed to contact.

August 2003 I called Bob Rebbling, Developmental Engineer for INDOT'S Greenfield office. Bob stated he would look into this situation and see what could be done.

Fall 2003: $\quad$ I contacted the ADA Coordinator of Indianapolis, Julie Paini. She too mentioned that this intersection was the states responsibility, but she would look into how she could help.

November 2003: I talked to Bob Rebbling of Ingot's Greenfield office. I was told that the expansion of U.S. 40 was scheduled for spring of 2006. I was not thrilled because I still needed to get across the road safely, since I'm blind.

April 2004: I collected letters of support from my elected officials. I got letters from Warren Township Trustee, State Rep. Lawrence Buell and State Senator Pat Miller. My city county representative did not respond to my request. Senator Miller sent a carbon copy to the Mayor of Indianapolis.

Summer 2004:

I sent a package of all these letters to Bob Rebbling of the INDOT Greenfield office. These letters expressed strong support, and suggested many ways to improve this intersection and help people with disabilities get across the road.

September 2004: I spoke with Mr. Rebbling again. He had read all the letters and was willing to talk about intermediate solutions to our problem at hand.

2005: $\quad$ Our Governor, Mitch Daniels decided to cut back on fixing roads and making them more accessible. I spoke with Mr. Rebbing several times. He was looking for ways to come up with a compromise, but I was told U.S. 40 expansion project was pushed back to 2010. 
Mr. Rebbling did suggest that the state could install audio crosswalks and signals if the city would do the concrete work. (Installing curb cut outs and connects intersection to existing sidewalk)

Fall 2005: $\quad$ The ADA Coordinator and the Liaison for Indianapolis Public Works conference called me. Both of them stated it was the states responsibility. They would look into this matter.

Fall 2005: $\quad$ I called ADA Great Lakes Center at UIC to ask about what I could do. I found out that this intersection is in violation of American Disabilities Act. This intersection does not provide accessibility to people with disabilities.

Fall 2005: I Ialked to the U.S. Dept. of Justice about my situation. I was told that yes, this intersection of U.S. 40 and Post Road was in violation of the ADA concerning accessibility for all people.

January 2006: $\quad$ I decided to turn up the heat on the city ADA Coordinator. I had a friend send her an email asking what is going on with the U.S. 40 and Post Road Intersection. This friend sits on the ADA State Steering Committee. The ADA Coordinator asked me Why Do You Want to Cross the Road? I could not believe her of all people, a person with a disability asked that question.

February 2006: I filed an official complaint with the Mayors Action Line.

February 2006 We had a meeting, myself and two other individuals with disabilities that use this intersection met with the ADA Coordinator and Attorney of the City of Indianapolis. At this meeting, I presented them with a petition having signatures from 30 businesses that I am a patron of on a regular basis. I MUST cross the road to get to these places. I also had two poster boards that were laid out with 21 pictures illustrating the poor conditions and the ADA violations. After we all had a change to talk and express our thoughts, the city's attorney stated they could not do anything about this intersection and it was the states responsibility. The city was not willing to compromise.

April 2006: I contacted all my elected officials to try something different. Senator Miller responded that she would make some calls. She talked to INDOT and found out that the U.S. 40 expansion project was moved up to 2008. She asked how I felt. I told her that was good news, but I was not ecstatic because I still need to cross the road and being blind that is not EASY. She said that she will continue to work on it.

May 2006: I called Tom Sharp, the Commissioner of INDOT. I explain to him the situation and my concerns. At first, I was told that there are no 
sidewalks out there. I quickly told him that I live out here and although you might not be able to see them because of over grown grass or deterioration they do exist. He did listen and stated he would talk with Mr. Rebbling of the Greenfield office.

May 2006: I talked to Mr. Rebbling. After talking with Tom Sharp, Bob found out that the U.S. 40 expansion project was slated to break ground in spring of 2007. Bob and I discussed what could be done on an intermediate basis. He is still going to talk to others with in INDOT.

The above time line was supplied by Mr. Greg Meyer. It illustrates the frustration encountered by the blind when an intersection is not ADA accessible.

\section{AVAILABLE APS HARDWARE}

There are thirteen companies that supply either piece parts or full APS systems for pedestrian intersections. The companies are listed below in alphabetical order.

1. Campbell Company, 211 West $37^{\text {th }}$ Street, Suite C, Boise, ID 83706, 877-3451727, website: www.pedsafety.com

2. Georgetown Electric, Ltd., 2507 West Second Street, Wilmington, DE, 19805, 302-652-4835, email: vipb98@aol.com

3. Mallory Sonalert Products, Inc., 7545 Rockville Road, Indianapolis, IN 46214, 317-273-0090, website: www.mallory-sonalert.com

4. Novax Industries, Inc., 658 Derwent Way, New Westminister, BC V3M5P8 Canada, 604-525-5644

5. Panich Consultancy Pty. Ltd., P.O. Box 360, Ryde, NSW 2112, Australia, 612 9809 6499,website: bobpanich.com.au

6. Panich U.S. Distributor, Summers Distributing, Gary Summers, 8902 Red River Ct., Bakersfield, CA 93312 USA, 661-587-7214, email: accessallpeds@,hotmail.com

7. Polara Engineering, 4115 Artesia Avenue, Fullerton, CA 92833-2520, 714-5210900, website: www.polara.com

8. Prisma Teknik AB, P.O. Box 5, S-543 21, Tribo, Sweden, (46) 504150 40, website: www.prismateknik.com

9. Prisma Teknik U.S. Distributor, Eagle Traffic Control Systems, 8004 Cameron Road, Austin, TX 78754, 512-837-8310, email:info@eaglets.com

10. Relume Corporation, 64 Park Street, Troy, MI 48083, 888-7-RELUME, 248-5852640, website: www.relume.com

11. Talking Signs Inc., 812 North Blvd., Baton Rouge, LA 70802, 888-825-5746, website: www.talkingsigns.com

12. U.S. Traffic Corporation, 9603 John Street, Santa Fe Springs, CA 90670, 562923-9600, website: www.ustraffic.net

13. Wilcox Sales Company, 1738 Finecroft Drive, Claremont, CA 91711-2411, 909624-6674, website: www.wilcoxsales.com 
These suppliers do not all have hardware that meet the U.S. Access Board guidelines as published in their second draft. For example, Talking Signs uses infrared transmissions from a building or other desired spot to be identified and the blind person points a special receiver and receives an audible identifying the site. However, this author has personally investigated the hardware that, in his engineering judgement, meets the U.S. Access Board guidelines II. This APS hardware is manufactured by Polara of Fullerton, CA. I have visited sites in Miami, FL, Morristown, NJ and West Lafayette, IN where their system has been installed and is currently being used by the blind. Miami Dade County, Florida has decided the Polara ${ }^{\circledR}$ System best meets their needs. I visited the newly installed site last September and wrote a summary letter to Mr. Dan Holder, Director of the Miami Dade Office of Americans with Disabilities Act Coordination. The letter is in the next section of this report.

\title{
Polara ${ }^{\circledR}$ System Site Visit at Miami, Fl
}

September 15, 2005

\author{
Mr. Daniel S. Holder \\ Director \\ Office of Americans with Disabilities \\ Act Coordination \\ 111 N.W. $1^{\text {st }}$. Street \\ $12^{\text {th }}$ Floor, Suite 348 \\ Miami, Florida 33128
}

Dear Mr. Holder:

The purpose of this letter is to summarize and comment on my site visit this morning to the intersection of $144^{\text {th }}$ street S.W. and highway U.S. 1. As you know, an accessible pedestrian crossing (APS) signal was recently installed on the north/south pedestrian crossing on the west side of U.S. 1. This APS was installed at the direction of your department and implemented by Robert Janosi of the Miami Dade Public Works Department Traffic Signal Division for the purpose of accessibility to a local bus stop for the blind and visually impaired. In addition to four blind users (three with canes and one with a dog guide); Robert Janosi; Maud A. Gonzalez, ADA Administrator for Miami Dade Transit office of Civil Rights and Labor Relations; Raul E. Rios, PWD, ADA Coordinator from the Public Works Department - Road, Bridge and Canal Maintenance Division and the Polara ${ }^{\mathrm{TM}}$ field representative from Daytona Beach, FL. along with others were in attendance.

The issues being examined at the intersection were sound pressure levels, audible signal types and timing, navigational directionality from the mast pole located pedestrian push buttons and intersection warning strips for the blind and visually impaired. 


\section{Sound Pressure Levels}

The intersection crossing is equipped with a Polara ${ }^{\mathrm{TM}}$ two wire system with capability for three languages- English, Spanish and one other. All sounds emanating from the speaker box/push button assembly are automatically modulated up and down about 6 dBA above background ambient noise. A 1.0 hertz locator tone emanates from a small box containing an integral speaker-pedestrian push button mounted at a convenient standard height on the nearest mast pole. This locator tone was detected by the blind subjects and vectored them to the vibro-tactile button which when pushed yielded a tactile feedback detent feel to the blind person and also queued the pedestrian signals for the next crossing phase. It was noted that the locator did, indeed, modulate the tone volume with background ambient noise level and that the tone was discernable about 15' from the tone source point.

\section{Audible Signal Types and Timing}

Upon our arrival at the intersection, the locator tone was working as expected and upon pushing the button, a standard voice said "wait", "wait". The safe to cross signal was an audible machine-gun staccato series of sounds lasting the standard seven seconds immediately followed by the clearance interval audible count down. For example, if the intersection is 80' across and if one assumes the pedestrian moves at 4.0 $\mathrm{ft} / \mathrm{sec}$, the count down will start from $20(80 / 4)=20$ seconds. However, this particular intersection clearance time was only nine seconds which was much too short for any sighted pedestrian let alone a blind or visually impaired pedestrian. The crosswalk travel distance was about 48' but fifteen feet must be added on each side of the intersection crosswalk since the push button is at least 15' from the non-existent curb and non-existent truncated dome warning strip which would tell the blind person where the crosswalk begins. So, the clearance time should have been $48^{\prime}+15^{\prime}+15^{\prime}$ divided by 4.0 , i.e., 78'/4 = 20 seconds instead of 9 seconds as was found this morning. As the pedestrian crosses the street and comes to the half-way point they begin to hear the count down from the opposite speaker box. In Addition to timing information, the count down gives the blind user a navigational aid to the opposite side of the street.

The audible signal type was changed from English to Spanish by changing the internal circuit board chip which allowed either language depending on the number of push button clicks. Additionally, the message was modified by Robert Janosi to be intersection specific by announcing "safe to cross $144^{\text {th }}$ street S.W. at U.S. 1 ". This is a great help to the blind. Moreover, this intersection specific message will be very important at an intersection where 10' spacing cannot be achieved between two speaker boxes and a possible ambiguity exists without the tailored message.

\section{$\underline{\text { Warning Strips }}$}


A major problem with this intersection was that no tactile warning strips (truncated domes) were installed in the pavement to tell the user where the intersection pedestrian crossing begins. Strips need to be installed.at the N-S crossing.

\section{Braille on Co-Located Sign Above Speaker Box}

Braille needs to be installed on the informational sign immediately above the speaker box. No Braille was found on the information signs. Also, care must taken during installation of the speaker box and associated information sign so that they are aligned parallel to the crossing directions as close as possible.

\section{Summary}

The installation of this pilot APS is critical to the success of subsequent APS systems in Miami Dade County and for impetus to the National Access Board to move forward on a national standard APS specification. Miami Dade County is to be commended for their progressive attitude regarding APS for the blind and visually impaired as evidenced by this pilot installation. The characteristic of this Polara ${ }^{\mathrm{TM}}$ system, which will be very important for acceptance of APS installations throughout Florida and the US, is that it is also helpful to sighted and elderly users.

Purdue University School of Civil Engineering and the Indiana Department of Transportation are very appreciative for the opportunity to visit and experience this site. Both myself and the blind subjects thank you for your efforts in this most important matter.

Sincerely,

Robert B. Jacko, Ph.D., P.E.

Professor of Civil and Environmental Engineering

\section{Two Examples of an APS Specification}

Examples of Specifications for an APS system are shown in the following text. . The first specification was written by the Miami Dade County Florida traffic light management director relating specifically to their needs in Miami Dade County. The second example was written for an APS system in a general or broad sense. 
Specification Example \#1

Technical Special Provisions

\author{
AUDIBLE-TACTILE PEDESTRIAN SYSTEM \\ FOR \\ ADA STANDARDS AND EQUIPMENT EVALUATION PROJECT
}

\title{
1.0 SCOPE
}

The purpose of this document is to provide minimum standards and requirements for the development of future standards and equipment specifications by the Public Works Department, for various ADA related pedestrian equipment for audible and/or tactile recognition of pedestrians that are physically challenged crossing our signalized intersections in Miami-Dade County, Florida.

\subsection{GENERAL REQUIREMENTS}

The Audible-Tactile Pedestrian System (ATPS) as described in the attached Functional Specification shall conform to all the minimum requirements as set forth by FHWA "Manual on Uniform Traffic Control Devices" (MUTCD); Florida Department of Transportation (FDOT) "Traffic Engineering Manual"; other pertinent FDOT Standards \& Specifications; and Florida State Statutes (FSS), for equipment, sale, installation, operation and acceptance for use in Miami-Dade County, Florida.

The Miami Dada County Public Works Department (PWD or Department) is the owner and maintaining agency for all traffic signalization control devices installed within the County right-of way and other designated roadways, open to public travel on County property. Therefore, the Contractor shall follow all PWD standards and equipment specification as set forth in the Department's manual "Traffic Control Equipment Specifications and Standards" and the latest supplements or addenda as referenced in the Special Provisions available from the Department's Contracts and Specifications Section. As for the ATPS described in the Functional Specification, all acceptance procedures, standards and requirements established by PWD in the above stated documents shall apply.

\subsection{STATE OF FLORIDA - MINIMUM REQUIREMENTS AND STATUTES}

\subsection{FDOT CERTIFICATE OF CONFORMANCE and/or APL}

Pursuant to Florida Statutes, Manufacturers are required to hold a current FDOT Certificate of Conformance and/or is listed on FDOT Approved Products List (APL). 


\subsection{FSS 316.003(23) Definitions.}

“OFFICIAL TRAFFIC CONTROL DEVICES - All signs, signals, markings and devices, not consistent with this chapter, placed or erected by authority of a public body or official having jurisdiction for the purpose of regulating, warning or guiding traffic."

\subsection{FSS 316.0745 Uniform Signals and Devices.}

"It shall be unlawful for any public body or official to purchase, or for anyone to sell any traffic control signal or device unless it conforms to the manual and specifications published by the Department of Transportation and is certified to be of such conformance prior to sale. Any manufacturer or vendor who sells any traffic control signal, guide, or directional sign or device without such certification shall be ineligible to bid or furnish traffic control devices to any public body or official without such certification shall be ineligible to bid or furnish traffic control devices to any public body or official for such period of time as may be established by the Department of Transportation; however, such period of time shall be for not less than one (1) year from the date of notification of such ineligibility."

\subsection{SS316.0755 Pedestrian control signals.}

"When pedestrian control indicators are installed, such indicators must conform to the requirements of the most recent Manual on Uniform Traffic Control Devices."

\subsection{PROJECT LOCATIONS}

The ADA Standards and Equipment (ADAS\&E) Evaluation Project for the ATPS shall be located at the locations shown on the revised signalization palns for Project number TA01-BWX-IN:

1) North Segment: At twelve (12) selected pedestrian signal head controlled crosswalks between south of SW 232 Street to SW 112 Avenue.

\subsection{EQUIPMENT APPROVAL REQUIREMENT}

Prior to the procurement of any of the Audible-Tactile Pedestrian equipment, the Contractor must obtain written approval from the Miami-Dade County Public Works Department and GSA Office of ADA approving the equipment to be utilized at traffic signalizations in the ADES\&E Evaluation Project. In order to accomplish this, the Contractor shall submit to the Office of Public Transportation Management Project Engineer (Engineer) eight (8) copies of the pertinent data for each item proposed for ADAS\&E Evaluation Project equipment. The submittal shall include copies of the manufacturer's FDOT certification letter/APL number. Any equipment 
installed without FDOT certification and/or installed prior to said approval may be cause automatic rejection and replacement at the Contractor's expense.

Approval must be obtained from the Public Works Department prior to ordering of equipment by the Contractor to avoid delays in time and/or rejection of proposed equipment. It will be advisable that this approval be obtained in adequate time to assure delivery within the time schedule set forth for the project. Delays in delivery will not automatically be considered a cause for extension of time. Also, all installed equipment must function properly at the time of signal turn-on.

In the event that signalization is delinquent and this places the project into the penalty period, no delays caused by the Contractor's compliance with these special provisions shall be cause for Miami-Dade County to grant the Contractor a time extension.

\subsection{SPARE EQUIPMENT}

The contractor must provide four (4) complete sets of spare equipment of the Audible-Tactile Pedestrian System to the Public Works Department, for replacement purposes only of any damaged or failed equipment on the project. The PWD shall maintain said system equipment after the successful completion of the standard Department burn-in period. The Manufacturer shall package the equipment in separate cartons, and identify each carton as spare equipment, indicating "ADA Busway Evaluation Project", project number and date of delivery.

The spare equipment shall be delivered to the Public Works Department, Traffic Signals and Signs Division facility located at 7100 NW 36 Street, Miami, Florida 33166 , at the time designated by the Engineer.

\subsection{QUALIFICATION OF WORKERS}

Due to the additional complexity required in the design, placement, operation and equipment of the ATPS and since this is an ADA Standards and Equipment Evaluation Project, it is therefore most important that the Contractor and their technicians are trained and qualified in the theory and operation of this equipment. The Contractor shall be required to have the Manufacturer provide training to his/her technicians and to the PWD signal technicians at a time and place agreed to by the Department. All other standard qualification of workers requirements of the PWD shall apply. The Contractor shall work very closely with the Public Works Department through the Engineer for proper operation and placement of the STPS equipment.

\subsection{FIELD INSTALLATION MEETING}


Prior to the installation of the ATPS equipment a field meeting shall be held with representatives of the Public Works Department, GSA Office of ADA, Office of Public Transportation Management (OPTM), Prime Contractor, Signal Contractor and Manufacturer's factory certified representative (one whose thoroughly trained in the installation, operation and trouble shooting of the equipment). Contractor's failure to have a Manufacturer's factory representative present at the meeting shall be cause to postpone said meeting and delay installation of ATPS equipment.

The field installation meeting purpose is to ensure the proper placement of the above equipment to comply with all requirements as set forth in the MUTCD; FDOT Traffic Engineering Manual; Manufacturer's installation/placement requirements; GSA - Office of ADA; the Public Works Department, Traffic Engineering; and Traffic Signals \& Signs Divisions.

The field installation meeting shall be required prior to the installation of any of the following signalization equipment:

1) Pedestrian Pushbuttons;

2) Pedestrian Signal Heads;

3) Audible Pedestrian Detectors; and

4) Aluminum pedestrian (signal or pushbutton) pedestals

\subsection{FACTORY REPRESENTATIVE (REQUIRED)}

This evaluation project shall require the Contractor to have Manufacturer representative(s) present for the field installation meeting and shall be present during the installation and testing of equipment. Failure to have factory representative present may be deemed just cause to prohibit the Contractor in proceeding with the installation of said ADA equipment.

\subsection{FIELD QUESTIONS and DESIGN MODIFICATION}

Due to ADA design/placement requirements that the ATPS must be installed within certain parameters in relationship with pedestrian ramps/crossings, proper placement of the ATPS equipment may require modification of the location of : pedestrian signal head(s) or pushbutton(s); pedestrian pedestals and possible addition thereof. Therefore, the Contractor is hereby advised that he/she shall work closely with the Engineer concerning this matter. The Engineer shall work closely with the PWD Traffic Equipment \& Specifications Engineer at (305) 592-3470 ext. 227) concerning any questions, problems or other concerns in regard to this project.

\subsection{EQUIPMENT WARRANTY REQUIREMENTS}

The standard Public Works Department policy of a three (3) year Manufacturer equipment warranty shall apply for all Audible-Tactile Pedestrian System equipment/components installed in Miami-Dade County, Florida. The warranty shall 
encompass and include only failures which occur as a result of normal operation of the ATPS. The warranty shall not include damage due to fire, flood, high winds, moving objects, acts of vandalism or sabotage, or other circumstances commonly known as Acts of God. The Manufacturer/Vendor shall bear all costs of repair or replacement in addition to the shipping of any equipment or other components, which fail because of normally occurring electrical or mechanical phenomena. Unit(s) and/or components which have been found to be defective by the Department will be removed from service by Miami-Dade County and packed for shipment by the County at no charge to the Manufacturer/Vendor.

The three (3) year warranty period shall commence at the data of installation into an operating environment or at the expiration of a one hundred eighty (180) calendar day shelf life, whichever may occur first. The one hundred eighty (180) calendar day shelf life shall commence from the date of receipt of the spare equipment by the PWD.

\subsection{CONFLICTS AND WAIVERS}

In every case the warranty and technical requirements of this document shall prevail over any other specifications or standards set forth by Miami-Dade County PWD. These specifications and requirements supersede all previous specifications and requirements and can only be superseded by Department addendum.

The Department reserves the right to waive, in writing, any portion or portions of this specification and requirement for the STPS.

Specification Example \#2 
FUNCTIONAL SPECIFICATION

FOR

AUDIBLE-TACTILE PEDESTRIAN SYSTEM

\section{GENERAL DESCRIPTION}

The Audible-Tactile pedestrian system shall consist of all electronic equipment, mounting hardware, power supplies, push buttons, and sign faces which are designed to provide both a raised vibrating tactile arrow along with a variety of audible sounds for different traffic signal functions. The systems shall consist of a Control Unit and Pedestrian Pushbutton Unit as described below.

\section{FUNCTIONAL REQUIREMENTS}

a) The button when pushed shall give both audible and physical feedback of the switches activation and an LED shall light and stay lit until the walk cycle begins.

b) The system shall include a raised tactile arrow which shall be field adjustable to allow alignment with the crosswalk.

c) System shall have built in walk/don't walk conflict detection so that should both come on simultaneously, the system will give only a locating tone or no sound.

d) The system shall vibrate the tactile arrow button during every time the WALK interval is displayed.

e) The system shall have the field-selectable function known as "Pushbutton Locator Tone". During the Flashing DON'T WALK and the DON'T WALK intervals, the system shall provide a tone that emanates directly from the Pedestrian Pushbutton and repeats at once per second (as required by the MUTCD).

f) The system shall have the field selectable function known as "Extended Push Activation". This means that the audible WALK message will only be activated and sound during the WALK message will only be activated and sound during the WALK interval if the button is depressed for a minimum of three (3) seconds.

g) The system shall have a rapid tick sound for the WALK indication which shall be approved by Miami-Dade County Office of ADA prior to installation.

h) The system shall have a rapid tick sound for the WALK indication which shall be approved by Miami-Dade County Office of ADA prior to installation.

i) All sound levels shall adjust automatically in response to ambient noise.

j) All electronic components and wiring shall operate within a temperature range of -34 。 to $+74^{\circ} \mathrm{C}$. 
The above specification examples can provide a good starting point for the development of an Indiana specification for accessible pedestrian signals.

\section{INTERSECTION RATING WORKSHEETS FOR APS}

Shown below are draft copies of an intersection worksheet that is in the process of being prepared under NCHRP Project 3-62. The forms can be used for evaluating intersections and crossings for prioritizing the installation of APS.

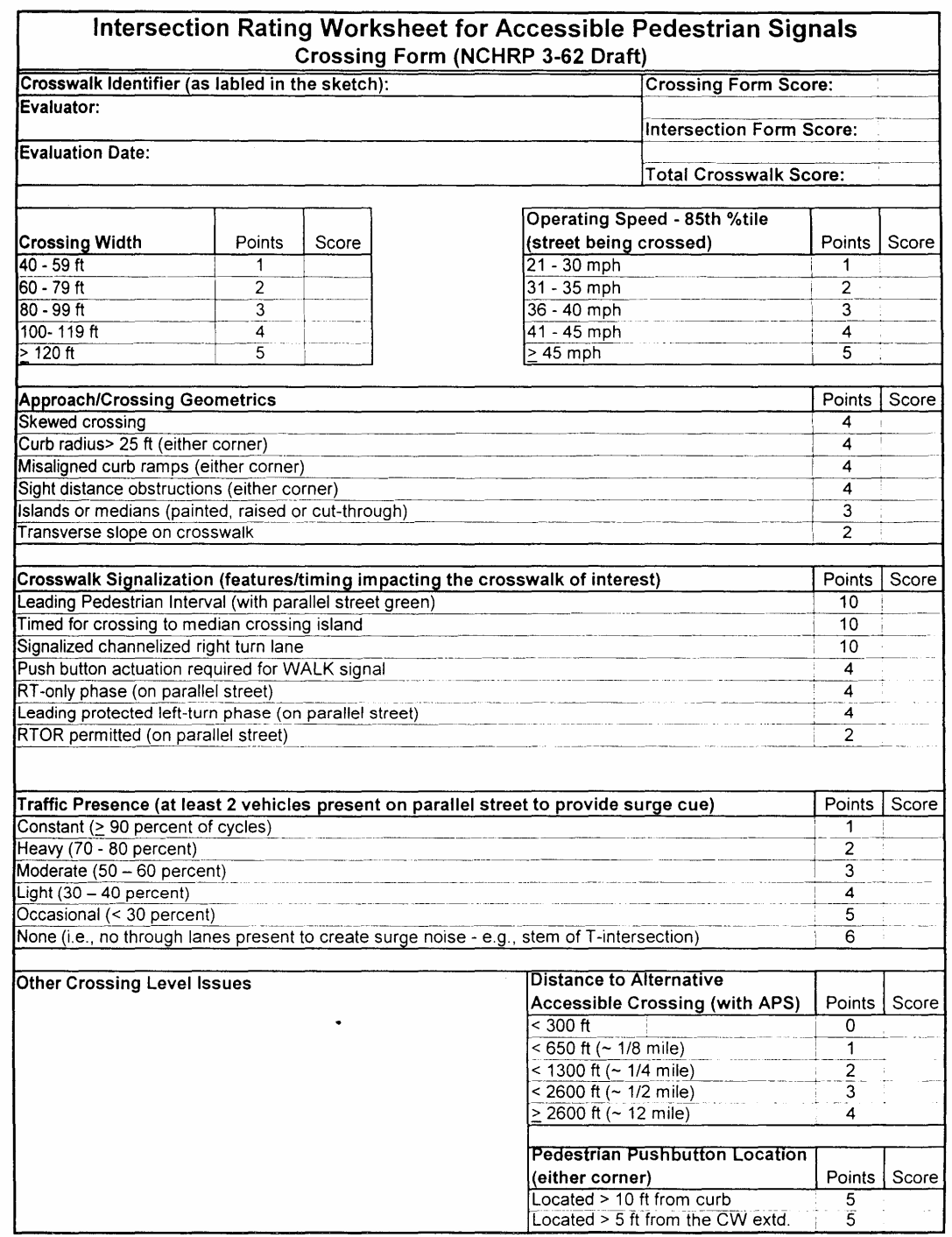

Figure 1 Intersection Rating Worksheet for APS (1) 


\begin{tabular}{|c|c|c|c|c|c|}
\hline \multicolumn{6}{|c|}{$\begin{array}{l}\text { Intersection Rating Worksheet for Accessible Pedestrian Signals } \\
\text { Intersection Form (NCHRP 3-62 Draft) }\end{array}$} \\
\hline \multirow{2}{*}{\multicolumn{3}{|c|}{ Location: }} & \multirow{2}{*}{\multicolumn{2}{|c|}{ Intersection Form Score: }} & \\
\hline & & & & & \\
\hline \multirow{2}{*}{\multicolumn{3}{|c|}{ Evaluator: }} & \multicolumn{2}{|l|}{ Crosswalk B Score: } & \\
\hline & & & \multicolumn{2}{|l|}{ Crosswalk C Score: } & \\
\hline \multicolumn{3}{|l|}{ Evaluation Date: , } & \multicolumn{2}{|l|}{ Crosswalk D Score: } & \\
\hline \multirow{24}{*}{\multicolumn{3}{|c|}{$\begin{array}{l}\text { Sketch: See instructions for information to include. Label crosswalks as } \\
A, B, C, D \text {, etc. }\end{array}$}} & Configuration & Points & Score \\
\hline & & & $4-\mathrm{leg}$ & 0 & \\
\hline & & & 4-leg offset/skewed & 3 & \\
\hline & & & 3-leg $(T$ or $Y)$ & 3 & \\
\hline & & & 5 or more legs & 4 & \\
\hline & & & Midblock location & 5 & \\
\hline & & & Signalization & Points & Score \\
\hline & & & Pre-timed & 0 & \\
\hline & & & Semi-actuated & 2 & \\
\hline & & & Fully-actuated & 4 & \\
\hline & & & Split phasing & $\begin{array}{c}6 \\
10\end{array}$ & \\
\hline & & & \multirow{2}{*}{\multicolumn{3}{|c|}{$\begin{array}{l}\text { Transit Facilities within a block ( 1/8 mile) } \\
\text { of the intersection - all legs }\end{array}$}} \\
\hline & & & & & \\
\hline & & & & Points & Score \\
\hline & & & $1-2$ stops/single route & 1 & \\
\hline & & & $1-2$ stops/multiple routes & 2 & \\
\hline & & & $3+$ stops $/$ single routes & 3 & \\
\hline & & & $3+$ stops/multiple routes & 4 & \\
\hline & & & transit mall/rail station & 5 & \\
\hline & & & Requests for APS & Points & Score \\
\hline & & & No requests & 0 & \\
\hline & & & 1 person & 4 & \\
\hline & & & 2 persons & 8 & \\
\hline & & & $3+$ persons & 12 & \\
\hline \multirow[t]{12}{*}{ Other Intersection Level Issues } & \multicolumn{3}{|c|}{ Crossing frequency by blind pedestrians } & Points & Score \\
\hline & \multicolumn{3}{|c|}{ None } & 0 & \\
\hline & \multicolumn{3}{|c|}{ Infrequently (< once/week) } & 6 & \\
\hline & \multicolumn{3}{|c|}{ Occasionally $(1-5$ times/week $)$} & 8 & \\
\hline & \multicolumn{3}{|c|}{ Frequently ( $>5$ times/week) } & 10 & \\
\hline & Distance to: & \multicolumn{2}{|c|}{ Visually Impaired Facility } & \multicolumn{2}{|c|}{$\begin{array}{l}\text { Major Pedestrian } \\
\text { Attraction }\end{array}$} \\
\hline & & Points & Score & Points & Score \\
\hline & $>2600 \mathrm{ft}(-1 / 2 \mathrm{mile})$ & & & 1 & \\
\hline & $<2600 \mathrm{ft}(-1 / 2$ mile $)$ & 4 & & 2 & \\
\hline & $<1300 \mathrm{ft}(\sim 1 / 4$ mile $)$ & & & 3 & \\
\hline & $<650 \mathrm{ft}(\sim 1 / 8$ mile $)$ & 8 & & 4 & \\
\hline & $<300 \mathrm{ft}$ & 10 & & 5 & \\
\hline
\end{tabular}

Figure 2 Intersection Rating Worksheet for APS (2)

\section{INSTALLATION OF POLARA SYSTEM AT PURDUE}

In August of 2005, a Polara ${ }^{\circledR}$ Navigator accessible pedestrian signal system was installed on the Purdue campus at the intersection of Stadium and University streets. This is the Polara two wire system which means that no additional trenching or pulling of wires under the street was required. The intersection originally was equipped with traffic 
signals and ped heads. Figures 3 through 6 show blind students and staff using the APS at the intersection of Stadium and University streets on the Purdue Campus.

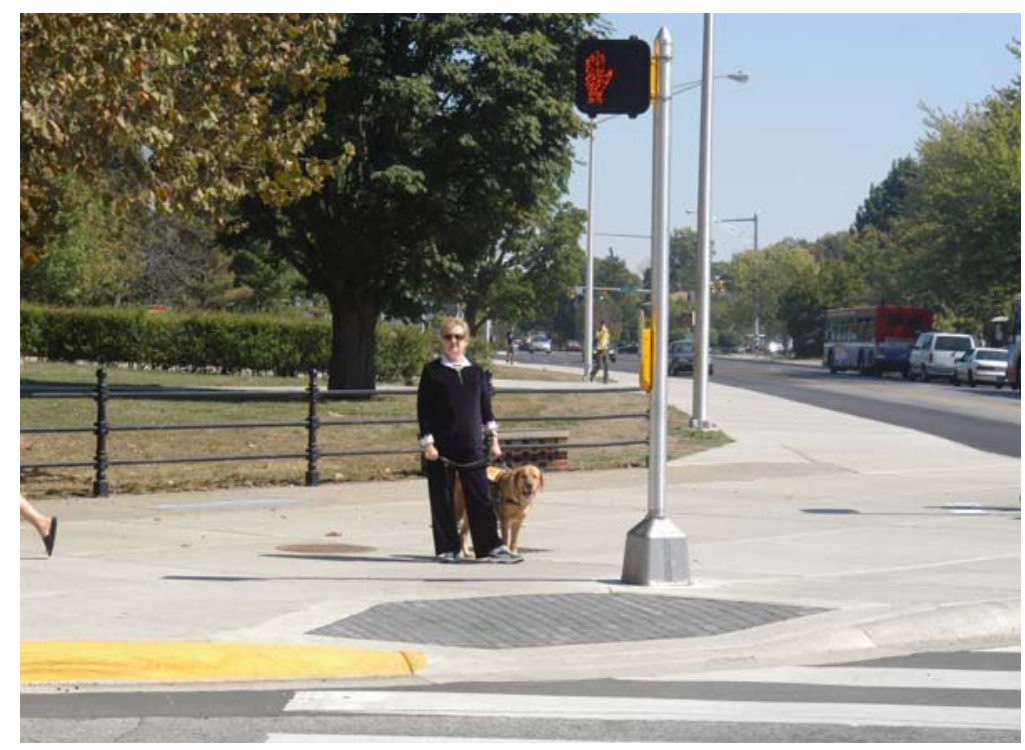

Figure 3 Blind pedestrian finds push button on pole using locating tone

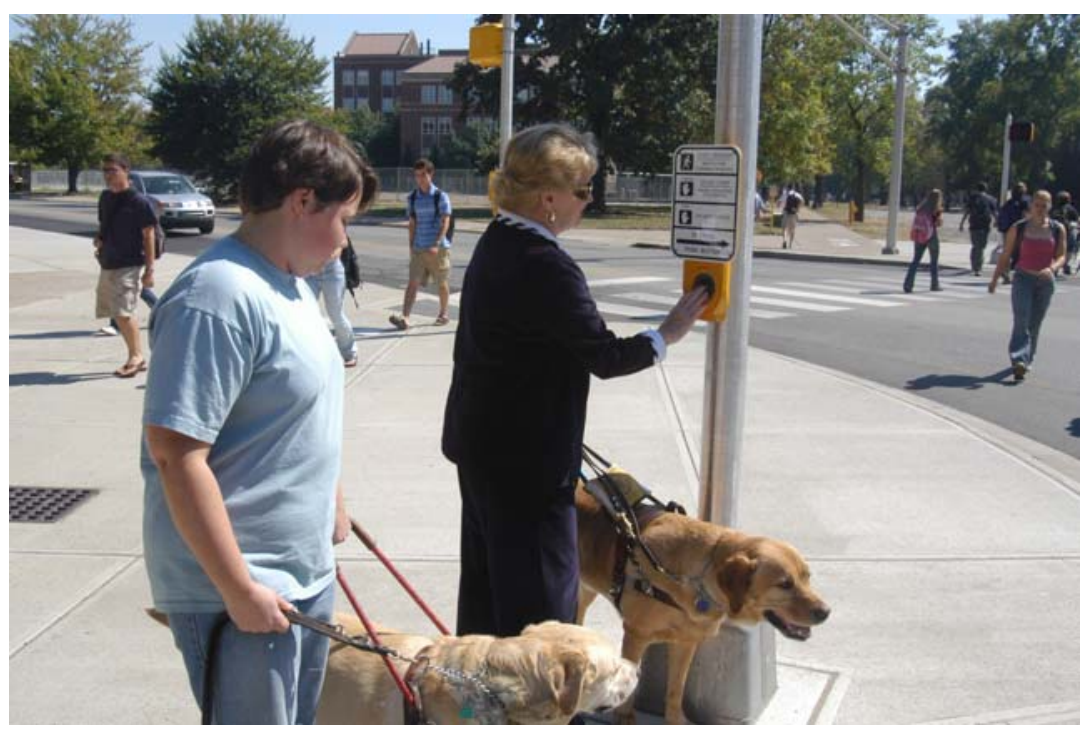

Figure 4 Blind Pedestrians with Guide Dogs Activate APS by Pushing Button 


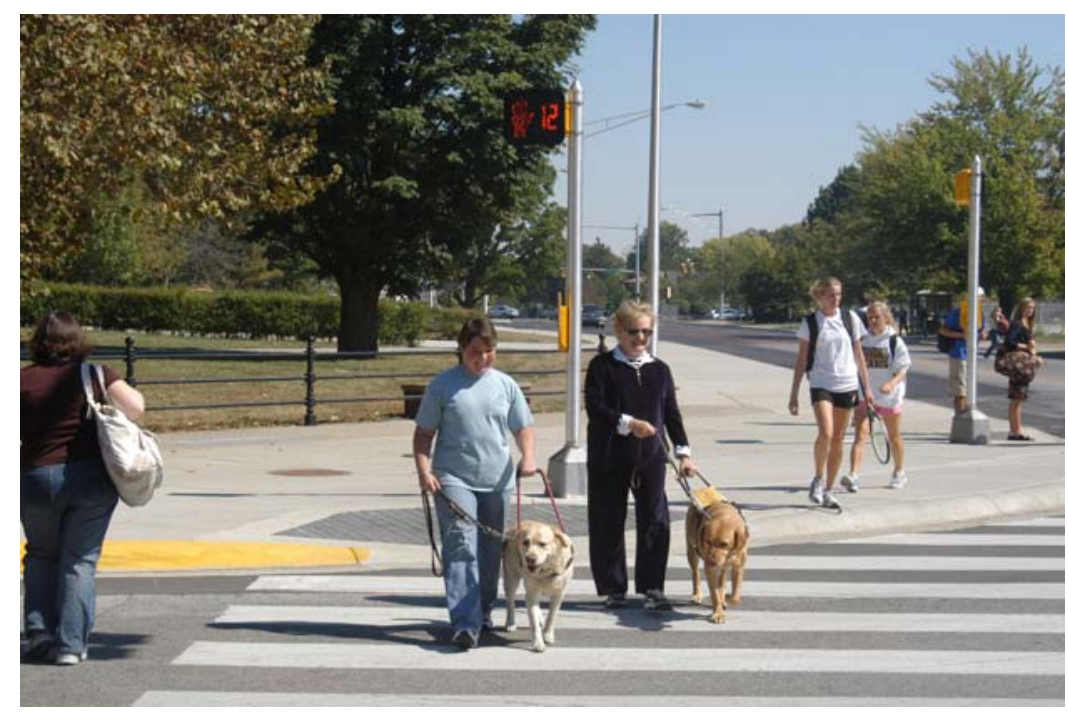

Figure 5 Blind Pedestrians Initiate Crossing on Audible "Walk Sign is On"(repeated three times followed by time countdown.

Figures six though eight show some of the details of the Polara system. Mr. Dennis Steele of the West Lafayette Traffic Signal Division maintains the Purdue system since the streets are within the bounds of the City of West Lafayette, IN. Figure 8 shows the Polara control box within the West Lafayette traffic signal cabinet.

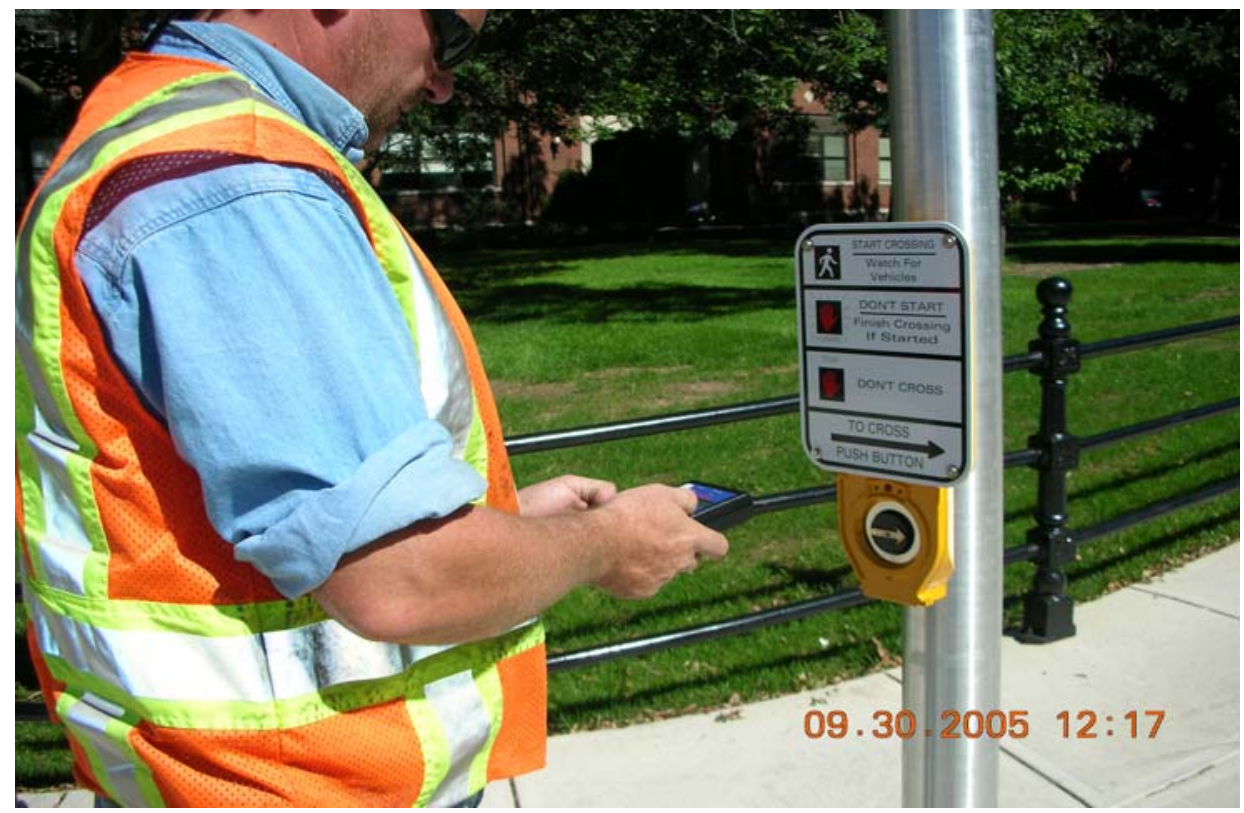

Figure 6 Traffic Technician Programs APS circuitry with Wireless hand held remote 
Note in Figure 1 that the Polara pole mounted push button/speaker/circuit box is programmable with a wireless hand held device similar to a TV remote.

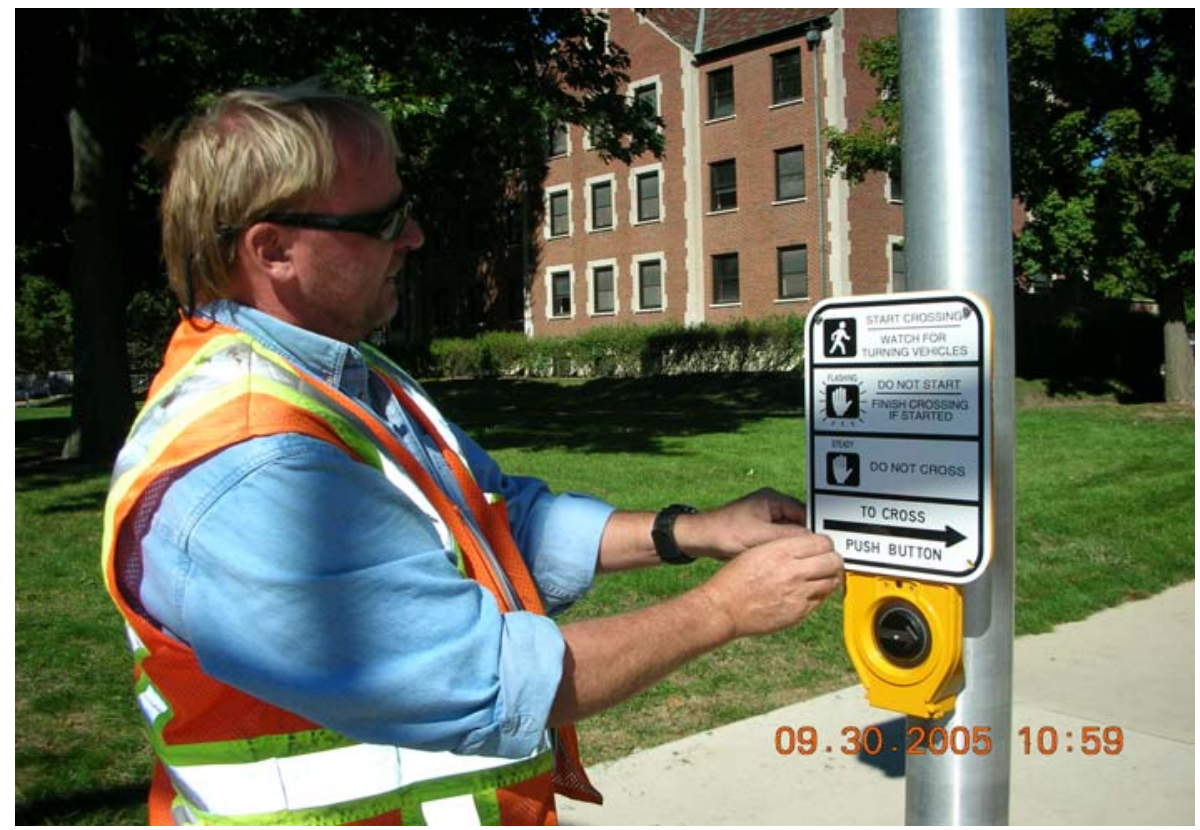

Figure 7 Disassembly of Speaker/Push Button Box

Note that the push button and attached sign for the sighted is mounted so that their flat surface is parallel to the direction of walking. In this way, the blind person knows the initial direction in which to walk. A problem at some intersections is damage due to motor vehicles crashing into the signs and an inexperienced technician installs the new signs not knowing that the button and sign must be parallel to the direction of walking. 


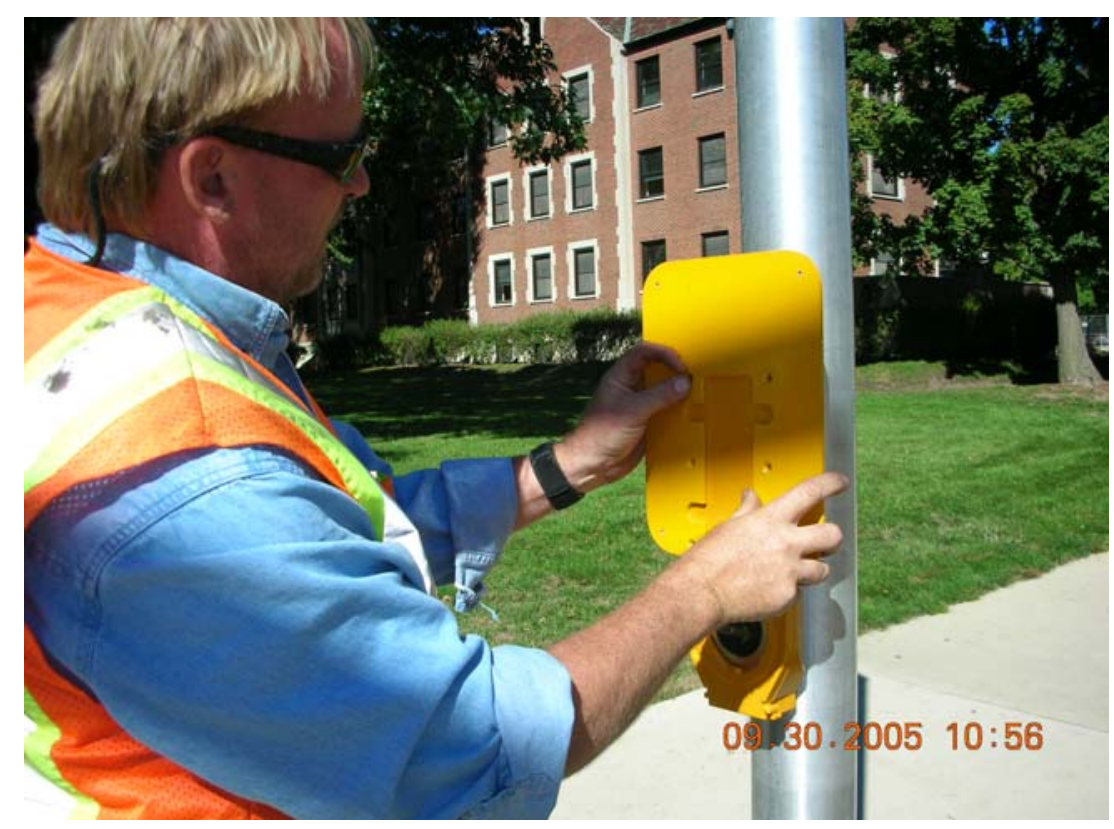

Figure 8 Removal of Printed Sign From APS Push Button Box

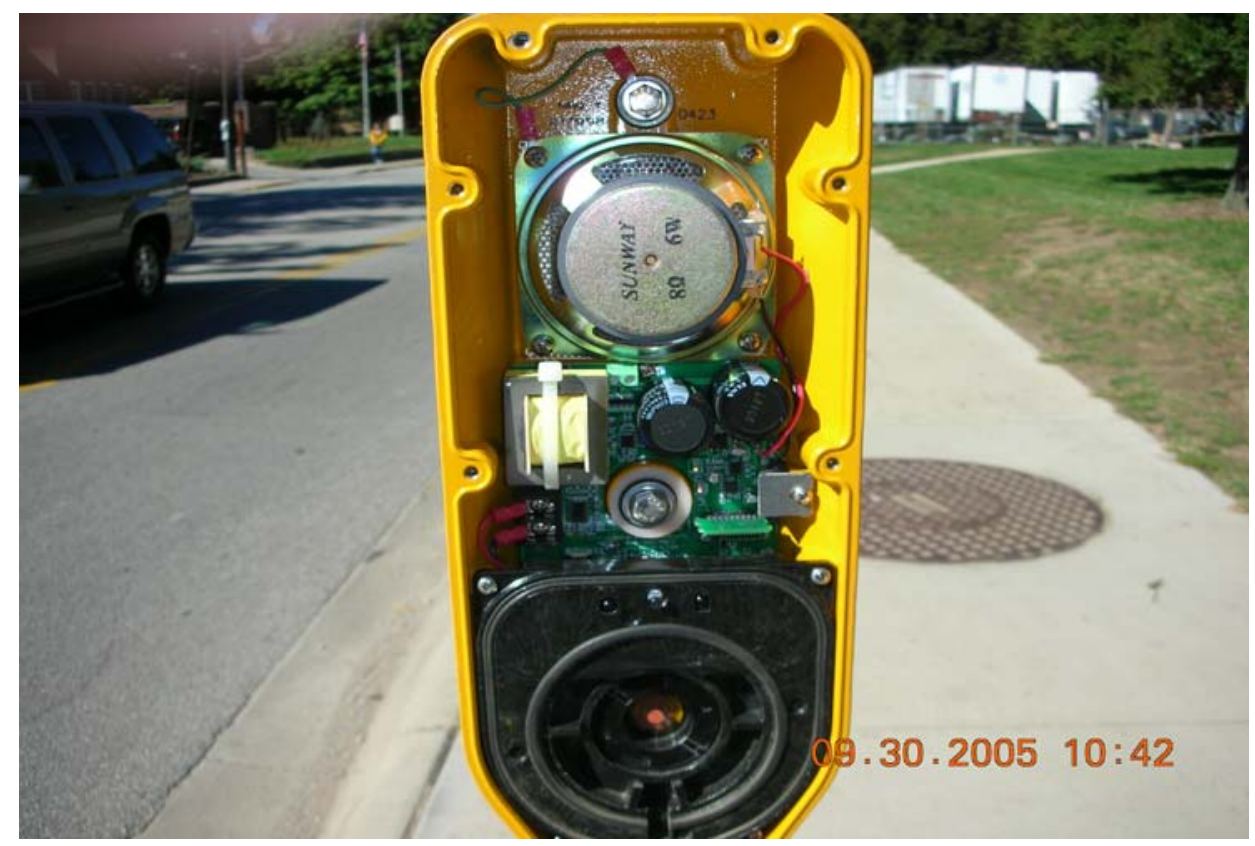

Figure 9 Circuitry Exposed in Speaker/Push Button Box. 


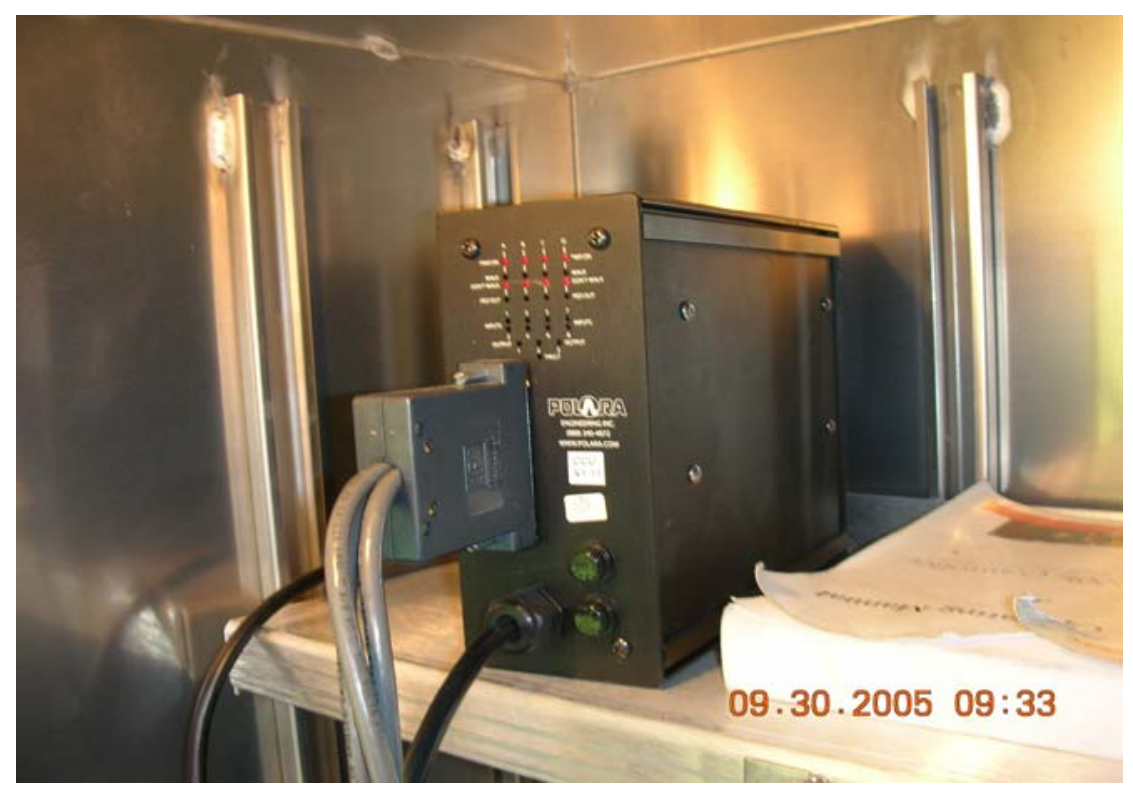

Figure 10 Polara Navigator Control Box Located in Traffic Cabinet

\section{SUMMARY}

Accessible pedestrian signal systems are available for installation at problematic intersections. This study resulted in the selection of a Polara Navigator system as meeting the current U.S. Access Board criteria. Experience with the Polara Navigator system installed on two very busy intersections on the Purdue University campus has enabled blind and visually impaired students and staff and the general public to safely cross these intersections. The Polara system is not a blind specific system tailored only for the blind. The vibrotactile and audible signals it emits also are understandable and easily usable by the general public who do not have disabilities. In other words, the system does not rely on unique sounds and procedures known only to a blind or visually impaired person. In this way, such a system benefits everyone and does not become a dedicated system understandable and usable only by a limited percentage of the general population.

The two wire Polara Navigator systems installs on an existing traffic light intersection without trenching or pulling new wire through conduits. A four-way intersection with existing traffic lights can be retrofitted with the APS system for about $\$ 3000.00$ hardware cost plus the labor cost for two men in four hours time. 